\title{
Snared:
}

\section{Ethics and Nature in Animal Protection}

\section{Adam Reed University of St Andrews, St Andrews, UK}

This paper will examine how animal protection investigators, lobbyists and campaigners in Scotland consider the relationship between nature and ethics. Specifically, it will look at the complex ways in which activists deploy the categories 'natural' and 'unnatural' in order to interpret realms of animal suffering and judge the actions of human and non-human agents in those fields. The paper is also concerned to chart the ways in which animal protection activists develop strategies for persuading various audiences of the rightness of their position; these include charity supporters and prospective donors, but also politicians and civil servants involved in the legislative process in the Scottish Parliament. More broadly, the paper engages with debates in the emergent fields of the anthropology of ethics and human-animal relations. It is interested in the relationship between ethics and appearance and in the distribution of agency in claims or judgments of ethical or unethical behaviour.

Keywords: ethics, nature, animal rights, law-making, campaigning

'There's badness down there,' Barry tells me as he lowers his binoculars and surveys the valley below us. I follow the direction of his gaze, which leads my eyes away from the exposed hills of the heather-bound moor around us, along the contours of a descending dry-stone wall and towards a small plantation of conifers. We set off, tramping once again through the long grass and trying to avoid the slope's many rabbit holes. Barry explains that he has identified a number of suspicious disturbances in the tree line: areas which he thinks deserve further investigation. After climbing the wall and jumping the fence beyond it, we reach the plantation and crouch down. With his trekking pole, Barry starts to examine the foliage breaks, gentling parting the low-lying branches and bracken in the hope of uncovering animal tracks or signs of human entry. 'Sometimes,' he informs me, 'the paths can lead you to badness. Sometimes I just smell it.' And with that, he opens a gap between the fir trees and disappears into the thicket.

What Barry is looking for is snares: wire loops, about the size of a watermelon, that are widely laid by Scottish gamekeepers to trap predator species, in particular foxes, on grouse- and pheasant-shooting estates. Cheap and easy to deploy, the snare wire is simply anchored to a stationary object in 
the vicinity, such as a tree or fence, and designed to tighten on contact. Snaring is a legal practice in Scotland, but Barry and the small animal protection charity he works for are campaigning to ban it on the grounds that it is a cruel and indiscriminate form of predator control. He is charged by the charity to monitor and record the legal and illegal use of snares, a form of evidence-gathering to assist the wider task of campaign lobbying. As Barry points out, his 'fieldwork' reveals that snares often do result in long, slow and painful animal deaths, and in the trapping of non-target species like deer and badgers. Indeed, this is the 'badness' of which he speaks and around which his investigations centre. He devotes time and energy to locating animal tracks in the woodland of shooting estates because these are gamekeepers' favoured sites for laying snares. Likewise, when Barry claims he can 'smell badness', he means he has learnt to identify and use the scent of decomposition to find living or dead trapped animals.

For all members of this animal protection charity, snares are a glaringly human technology. They provide a simple but discrete example of the largescale exploitation and abuse of wild animals in the Scottish countryside and of the general indifference to their ordeal. Snares and the shooting estates they are found on are taken to embody the false assumption that humans are superior and exceptional beings with the right of domination over other living creatures. In this regard, the charity's views conform to the broader critique of industrial humanity offered by the Euro-American animal rights movement. Snaring is but one more example of the cruel and prejudicial treatment of nonhuman animals, a form of injustice that mirrors or even exceeds human cruelty to its own species (see Laidlaw 2010a: 67-68, Song 2010: 55-56). Crucially, as the parallel suggests, animals are figured as victims, philosophically equivalent to human subjects in their relative capacity to suffer and experience pain. Like animal rights organisations and other animal protection organisations (the distinction is hazy, but in general the former are more focused on the idea of animal liberation and protest, the latter on the idea of animal welfare and petitioning), the charity sees itself as an advocate for the reduction or abolition of that unnecessary suffering. This includes the ambition of challenging the tendency to consider animals as resources, fit for human ends. 
The reasoning and judgments of these charity workers, including Barry's graphic identification of badness, makes clear that subjects believe they are operating in an explicitly ethical terrain. For them, the laying of snares is a breach of moral responsibility: it highlights a division between right and wrong acts, invites the attribution of blame and clarifies the virtue of their charitable work. Indeed, like other animal rights and animal protection agencies, members understand themselves to be involved in 'ethical campaigning'. Collectively and individually they are concerned to cultivate an ethical career. Such an emphasis prompts this essay's engagement with the recent 'ethical turn' in anthropology, centred round the concern to 'theorise and document the centrality of ethics for human life' (Lambek 2010: 5). In particular, I am interested in the suggestion that anthropological attention should fall not just on ethical self-fashioning (Foucault 1990; \& see Faubion 2011), but also upon the ethical as a dimension or modality of practice and action (Lambek 2010: 10, \& see Laidlaw 2010b, 2013). As Lambek points out, in common use the term 'ethical' has a double meaning - it can refer to the positive value placed on specific kinds of acts and to the general field in which criteria are laid out and judgment of action exercised (2010: 9). Charity workers deploy both usages. But, as I explore, ethics is not a sufficient ethnographic category to articulate the rightness or wrongness of an action such as snaring. At least for the animal protection charity I worked with, another mediating category is required.

As Haraway (1991: 1) once highlighted and the contributors to this issue continue to demonstrate, the construction or deployment of nature is at the heart of Euro-American debates about how one should live, 'perhaps the most central arena of hope, oppression, and contestation... in our times'. Its definition or redefinition continues to allow subjects, among them the workers of the animal protection charity I know, to differentiate their position, animate claims to good or bad behaviour and 'refigure the kinds of persons we might be' (1991: 3). This is so despite the fact that nature at times appears 'detraditionalised' (Franklin 2000: 190; \& see Strathern 1992), in danger of losing its axiomatic moral status in the face of new technologies and knowledge. Indeed, for Barry and his colleagues at the animal protection charity, ethics and nature are vitally intertwined. The latter gives form to their notion of moral 
authority and the former provides a language by which human relations to non-human animals can be described. The critiques provided by some of the category's closest observers (see Haraway 2003, 2008, Latour 2004), which point out the ways in which nature can deny or obscure precisely the kinds of human-animal attachments whose acknowledgement might offer an alternative moral basis for relating, may challenge that link but for the charity workers, nature continues to nuance the twists, turns, and risks of their ethical lives. Furthermore, the concept is vital to ethical reasoning. This includes the confirmation of animal rights, but also the suggestion that their ethical awareness might exceed that argument. In all these convolutions, the essay remains firmly focused on the importance for charity workers of the orienting figure of the snare and its accompanying actions, the practice of snaring and the experience of being snared.

\section{The (Un)natural World}

For Barry, the implications of snaring are both direct and personal. Indeed, as the charity's field investigator, he is the only one who confronts snares in situ. These traps, he tells me, are not just human interventions in the Scottish rural environment, they are indicative of what he holds to be a completely denatured national landscape, precisely crafted for the purpose of killing. The moor and narrow valleys we tramp across, he points out, take their form from the requirements of the grouse shoot. So, estate managers plant woodland or lease out land for conifer plantations to encourage predators such as foxes to live and breed there and hence make trapping and control more efficient. They keep the heather and other foliage on the moors distinctively low through regular burnings in order to force new growth for the grouse birds to feed on and to ensure wide, clear-view spaces for the sport of shooting parties. As Barry elaborates, the more iconically wild and remote parts of Scotland also tend to be estate-run. If not designed for grouse or pheasant shooting, they operate to facilitate highly economic activities such as deer stalking or fly-fishing. If one includes the vast tracts of farmland, in Barry's eyes organised for the industrial rearing and slaughter of animals arbitrarily designated as livestock, then agrarian Scotland is not just the 
context for acts of human cruelty to non-human animals, it is itself part of that technology. Badness is literally everywhere. In fact Barry complains that his investigations leave him unable to enjoy the countryside. For he can't help seeing the sinister human motivations behind the aspects that others take as innocent rural or wild scenes.

And yet nature does intrude. Snares may be a human technology but, as already noted, they tend to be laid along the paths of non-human animal tracks. Barry (and the gamekeepers who lay them) knows that snares are only effective if they are set in the right place, with an appropriate knowledge of predator behaviour. In this regard, one might speak of snaring as a practice that requires both wire loop and animal track to work together; it is only in tandem that they form a successful trap. So it is possible to identify what Barry regards as a 'natural' topographical feature at play here, and not just a vision of a hyper-cultured, denatured environment. Actually Barry automatically considers the animal tracks he discovers on shooting estates as an effect of the regular movements of predator and non-predator species over time whose actions he also identifies as a series of 'natural' behaviours. While the laying of the snare by the keeper is a cruel and 'unnatural' act, Barry assumes that the predations of the fox are within but at the same time outside the bad, interventionist environment of the estate.

Such acts of identification are conventional to all members of the animal protection charity. Concretely, the work of carefully and consistently differentiating between the natural and the unnatural animates much of what the organisation does and how its staff individually feels about the relationships between humans, their traps and non-human animals. The opposition provides the premise for campaign actions and the target for political lobbying. It defines the basis for critiques of human action as unethical and for explaining the differences between certain kinds of animal behaviour. Far more pervasive than the perhaps more studied and regularly highlighted dichotomy between nature and culture, this separation is crucial. Charity workers then still regularly deploy the concept of nature but in a way that suggests the field outside it is a purely negative space. Indeed, I want to suggest that in this rendering the realm of the denatured or unnatural carries a quite distinct trajectory from the realm of the cultural. 
As Eilidh, the charity's chief executive told me, 'natural acts are ones in which one has no choice.' They are instinctive kinds of behaviour and in the case of non-human animals vitally linked to the 'fight for survival'. So the fox hunts and kills the grouse because it needs to eat. One cannot, she states, say the same for the gamekeeper who lays his trap or the shooting parties who aim to bag a brace. Although both actions may involve the prey animal experiencing equivalent levels of pain and suffering, there is no deliberate cruelty or badness behind the former killing. Eilidh explains, 'the fox does not intend the grouse or pheasant to suffer, it just intends to survive.' Once again the distinction drawn is with the calculating, considered and hence unnatural motivations of the human actor. As Song (2010: 39) points out, the concept of 'killing for fun' is a key differentiator of human action in much animal rights discourse. Outrage at organised shoots, for instance, is often articulated through a critique of non-utilitarian slaughter. This charge is certainly picked up by the animal protection workers I knew, who also decry grouse and pheasant shoots on that basis. Although the clear instrumental purpose of snaring, in the economic management of an estate, means it does not quite fit the accusation of killing for killing's sake, it remains unnatural and wrong because it too detaches action from genuine needs.

More broadly, the identification of natural and unnatural acts is a discussion or reflection on relative culpability. As Laidlaw (2010b: 153, 2013) outlines, assignments of responsibility are central to the definition of an ethical field and the 'constitution and extension of the self'. Such attributions may include the revelation of hidden motivators, such as intention or temper (2010b: 157). They may locate accountability with the perpetrator, but equally show that 'agency has sources other than those "inside" the individual' (2010b: 152). Laidlaw highlights, for instance, the complex attributions at play in the various defences of 'involuntariness'. In this context, the natural seems to operate as a wholesale form of mitigation or to preclude the necessity of mitigation altogether, it describes an involuntary non-human actor who acts out of need and hence escapes any kind of responsibility for actions. Eilidh and the other charity workers would state that there is no malice or pleasure in the actions of the fox hunting the grouse, or at least if there is, the only determining factor is the fight for life. By contrast, the unnatural seems to draw 
judgment and accountability toward it. The human actor described is constitutionally wilful or an intermediary for the wilfulness and choices of another. Charity workers would hold the grouse shooter who kills for fun morally responsible for his or her actions, which are taken to reveal intention and state of mind. They may also hold the gamekeeper individually culpable for laying snares, though in this case determining agency and hence primary blame may be assigned to the keeper's employers. It may even be attributed to the whole animal-industrial complex that makes shooting and the wider exploitation of non-human animals possible.

Indeed, it is not just the fact that gamekeepers and estate managers have the choice not to snare wild creatures that makes their actions unnatural and immoral. For Eilidh it is also a question of 'scale' - as she admits, 'nature's cruel in some ways, and you will find examples of it through all animals. But again humans somehow have just blown it out of all proportion.' The fox, then, may kill and eat many birds over time, but each killing is an individual act between predator and prey in a natural environment. By contrast, the gamekeeper inflicts multiple injuries and deaths simultaneously. Not only does he lay tens or hundreds of snares across the estate, he is also absent at the moment animals are trapped and often at the moment they are killed. As Eilidh concludes, 'I feel it is only because we are detached that we are able to do it on that elevated scale.' Snaring then is wrong partly because humans themselves have found a way to avoid the constraints of the natural order. 'I would say we are part of nature,' Eilidh muses, 'but I think society is becoming more and more denatured. I think it's inevitable that we become less close to nature.' So it would seem that humans in some senses are or soon will be constitutionally unnatural.

This creates some confusion, especially when charity workers move from identifying the human abuses and exploitation of non-human animals to trying to distinguish what might make some human actions natural. 'Family units, I would say, mother and baby,' one staff member responded when I asked, 'yeah that would be the most natural.' But even as she thus speculated, the woman questioned her own designation: 'You find that a lot of people don't have a natural instinct to be with their own kind, and I would say that's quite rare in the animal world, unless there is something wrong with the 
creature.' As self-consciously liberal secularists, the animal protection charity workers are more confident in their designation of actions or attitudes they regard as conservative or reactionary. Thus the death penalty is easily rejected on the basis that it is a state-planned, premeditated and hence 'unnatural' form of killing. And same sex partnerships are actively embraced as perfectly 'natural' relationships, on the grounds that individuals do not choose their sexual orientation. Although it is rare for them to describe nonhuman animal actions as unnatural, there are notable exceptions, almost always connected with what they regard as human interventions. Zoo animals display unnatural behaviour because they are placed in an unnatural environment; likewise fighting dogs or pedigree pets, whose unnatural behaviours or postures have been reared or 'inbred' in them by generations of human owners.

Of course the wider dilemma circulates around the issue of ethics itself. In imagining humans as detached from nature, charity workers may at times deploy the category as an ethical concept or talk as though the natural and the moral are conjoined categories. But they are insistent that non-human animals are not proper subjects for ethical judgment. As already suggested, the fox may act naturally in killing a grouse, but it is not acting in a moral domain, at least in a manner that means it can be held to account. Indeed, here the natural, linked to the notion of instinct and the principle of endurance, seems to actively exclude the ethical. Only human beings, the potentially unnatural and hence morally dubious animal, can choose to behave well or badly. On the face of it, this is a position that seems to reinforce the denaturing of the world that animal protectionists bemoan, to confirm the inevitable separation of humans from non-human animals.

\section{Animal Protection Versus Environmentalism}

Evidence on the Wildlife and Natural Environment (Scotland) Bill: Stage 1

Elaine Murray (Dumfries) (Lab): Okay. We move to snaring, which is 
probably even more contentious. We had conflicting views about the need to use snares when we visited the Langholm moor demonstration project last week. Simon Lester, the head gamekeeper, told us that in some cases there was no alternative... Obviously, that is not the view of groups such as... [the animal protection charity I worked with are here named]. What are the views of LINK members on snaring? Do any of your members use snaring? Do you believe that it is necessary, particularly for successful grouse shooting or game management? What are your views generally on the argument that snaring is an indiscriminate trap? ...

Lloyd Austin (Scottish Environment LINK): Rather like the previous question, this is an area that is very much dominated by animal welfare issues, which are not an area of our expertise, which is much more in conservation and population management issues. That is why, collectively, LINK has not done any work on snaring. I will ask the panel members who represent organisations that are land managers to comment.

Mike Daniels (Scottish Environment LINK): The John Muir Trust does not generally do predator control, and we certainly do not snare... Our main reasons for not snaring are... that we are concerned about the indiscriminate nature of bycatch, with otters, pine martens, wildcats and other species getting caught in snares. As Lloyd Austin has indicated, we do not really take a position on the welfare side, although we are obviously aware of concerns from some of our members about welfare issues in relation to snaring.

The extract above is a section of the verbatim transcript from a consultation stage hearing of the Rural Affairs \& Environment Committee of the Scottish Parliament. Witnesses from 'stakeholder' organisations have been invited to respond to Committee members' questions as part of the process of scrutiny into the Wildlife and Natural Environment Bill. This is everyday business for the animal protection charity I worked with; the organisation prides itself on its reputation as a respected animal welfare lobbyist that is regularly asked by both government and parliamentary committees to submit evidence. This Bill in particular drew their interest because it was the first piece of primary legislation in many years to directly 
address issues of wildlife and countryside management, and to include specific clauses on the practice of snaring. However, although the charity is named in the extract above, the conversation recorded is actually between a Member of Scottish Parliament (MSP) and a number of witnesses from an umbrella group of Scottish environment or conservation bodies. I choose to quote it because I think it illustrates another dimension of the animal protection perspective, one that helps further draw out the ways in which ethics and nature and the opposition between the natural and the unnatural play out for them.

Indeed, my attendance at these parliamentary committee hearings and my close involvement with the lobbying work of the charity on snaring revealed an aspect of animal protection that, at least to me, was entirely unexpected. During fieldwork, I was struck by the realisation that the charity figured itself not just in opposition to the interests of what they would see as obvious agencies of badness or animal cruelty such as industrial farming and shooting estates, but also through a complex alliance and tension with environmentalist outlooks. In fact, at times, that latter distinction appeared more crucial to their self-definition as ethical campaigners; members of the charity would regularly point out to me the ways in which for them an animal welfare or protection position contrasted with and overrode the priorities of conservation (although at the time unknown to me, I subsequently learnt that this tension has garnered some recent commentary [see Bekoff 2013]). The emphasis jars partly because, as charity workers themselves admit, the general public fails to see the division; an assumption exists that supporters of animal welfare will also be supporters of environmentalism. It further surprises because at one level both perspectives share a remarkably similar ethical stance on human action (see Laidlaw 2010a), which for the purposes of critique is usually figured as behaviour disconnected from nature and damaging to natural order.

As the extract above highlights, this tension is also something that clearly works in reverse. When the MSP asked the umbrella group delegates for their opinions on snares, they immediately prefaced any comments with the bracketing observation that this is a substantively 'animal welfare issue' and hence outside their sphere of expertise. The second witness goes so far 
as to say, 'we do not really take a position on the welfare side'. To me, such responses seemed very odd, especially given the fact that the conservation groups they represented were themselves Scottish landowners and managers who had taken a deliberate decision not to lay snares on their estates.

Certainly, for Maggie, the policy director of the animal protection charity I work with, these replies and the general failure of the conservation groups to outright condemn snaring or comment on the treatment of trapped animals is a source of constant frustration. While her witness testimony to the Committee also mentioned problems identified by the conservation bodies, such as the indiscriminate nature of the trap, it was roundly focused on the submission of evidence demonstrating the manner in which snared creatures feel pain and injury. 'The cost in animal suffering is so high,' Maggie told them, 'that I would like the Committee to consider what is acceptable and what we should legislate for.' Time and again, it is on this basis that she makes her appeal.

The stress is important because it highlights what for Maggie and the other charity members is the crux of the difference between animal protection and conservation. In appealing to animal suffering, she is placing primacy firmly on the life and experience of individual living creatures, their right to be treated with respect and not be subject to human acts of cruelty. This should be the starting point, Maggie invites, for any legislative action. Behind that assertion is a general assumption that the natural world is a place precisely animated by these individual lives, a fact that for charity workers provides the basis of moral equivalence between human and non-human animals. In its individuality, then, humanity can be refigured as part of nature. What we naturally share with foxes and grouse is 'sentience', 'personality' and 'feeling', an awareness of a world around us and a capacity to both negatively and positively experience and respond to it.

As several charity members emphasised, this is patently not the perspective of environmentalism. 'Well fundamentally I suppose,' Maggie told me, 'the difference is that our priority is the welfare of individual animals, whereas a conservation organisation, their priority is numbers of animals and populations.' In this latter view, the natural world is a place animated by species and by particular ecosystems that need protection. Typically, focus lies on species survival, 'carrying capacity' of environments and the need to 
find 'balance' (see Berglund 1998). The stress placed on species interdependency means that individual creatures are ultimately subsumed by genus and that no species, at least in its contribution to sustaining habitat, should get left out of the environmentalist's moral concern. By contrast, the accent placed on consciousness in animal protection, as in animal rights (see Song 2010: 133, Rigby 2011: 87), allows for the proposition of abstract scales of natural comparison between individuals within and across species and between species types. It also enables their respective ranking. Plants, for instance, are typically excluded from the moral care of the charity workers I knew, and debates rage among them about the relative worth of insects and other consciousness-low or lacking creatures. Although the animal protection charity and conservation groups sometimes find bases for cooperation in lobbying work and usually collectively figure themselves against commercial interests in land management, who they depict as neither concerned with the welfare of individual animals nor with the protection of animal populations, the relationship ultimately always breaks down along that fault line (none of these actors publicly evoked 'Compassionate Conservation' or other recent attempts to resolve the tension between animal protection and environmentalism [see Bekoff 2013]). This does not mean that charity members don't deploy categories of population and sometimes of inter-species relations or that conservationists don't sometimes dwell on the characteristics of an individual animal, but it does mean that they both equally struggle to communicate formal ethical positions from these alternative levels or points of engagement with what they both take to be the natural world.

The contrast may be drawn out another way if we look at one recent attempt to bridge the gap between animal rights and environmentalist ethics. I am thinking of the rearticulated theory and practice of responsibility put forward by Haraway $(2003,2008)$. She wishes to maintain the notion that particular animals deserve regard at the level of individual and kind (genus or species), however at the same time challenge the assumption that these units of being are the proper measure of ethical concern. For her, 'mattering' always exists inside specific relationships (2008: 70). This includes connections between individual human and non-human animals and between humanity and other species. The point is not just that this focus better reflects 
Haraway's re-envisioning of nature as 'entangled assemblages of relatings knotted at many scales and times' (2008: 88). It is also that it offers a means to refigure the criteria and terms of ethical care. Seen from this perspective, she proposes, non-human animals are not straightforwardly victims and humans are not the only significant agents in a moral realm. Indeed, Haraway holds that an acknowledgment that what matters takes place inside tangible connections crucially allows one to consider particular human and animal actors as co-respondents (2008: 71). They may not be equal or symmetrical partners, but they are conjoined. Here, 'responsibility is a relationship crafted in intra-action through which entities, subjects and objects, come into being' (ibid). It is not or cannot just be a unidirectional obligation upon the human; Haraway makes clear that key drivers of animal protection and animal rights, such as the minimisation or relief of animal suffering, are not in her schema sufficiently responsible. If one insisted on maintaining the language of rights, she observes (2003: 53), then these would not be rights that existed a priori or preformed, attached to the natural state of individual or species being, but rights that emerged over time and in specific relational contexts; for instance, the mutual rights of respect and attention that cat and human owner may establish in each other.

Although Haraway's idea of responsibility as a phenomenon of specific relations and not just of human agency in many ways serves as a critique of the animal protection position (and that of classic environmentalism), I believe that there are elements of her argument that might appeal to members of the charity. Most strikingly, the presentation of human-animal relations as particular, historically inter-subjective and mutually responsive chimes with the way many of them narrate their own relationships with specific pets or companion animals. Individuals explicitly and implicitly nod to this copresence in their lives and regularly contrast the quality of that interaction with the more conventional relationships of pet 'ownership' that they perceive in Britain. But the sympathy for Haraway would completely break down at the point she tries to introduce other kinds of human-non-human animal interactions into the sphere of responsibility or moral concern. Notably, charity workers would outright reject the suggestion that instrumental kinds of relationship, for instance in farming or animal testing, might also be rendered 
as co-responsive or intra-active. The insistence that human induced animal suffering cannot be contained within the category ethical or the realm of natural or responsible actions ultimately restricts which connections matter, a fact that also reinforces the division with environmentalism.

For members of the animal protection charity, the obvious illustration of this opposition is the act of culling. As the quoted evidence of the parliamentary committee witnesses makes clear, the outstanding 'conservation issue' around snaring is the problem of 'bycatch': the fact that these wire loops can trap non-target and endangered Scottish species such as capercaillies, pine martens or otters. Formally, then, conservationists have nothing to say about how the target species is trapped or killed. In fact, while they don't use snares on their estates, they do carry out predator control. Such culls are performed in the name of environmental rebalance or favoured species protection. Conservation groups, then, will consider and do support the killing of individual non-human animals in the interests of what they view as the bigger picture of 'population management'. This is something the animal protection charity would never endorse. In fact, they actively campaign against it. Their argument is not just that the individual life of the animal must come first, but that the whole notion of humans acting to sustain the environment is misplaced and wrong thinking. Once again, the issue falls on what is natural and whether humans have the right to interfere in the struggles between non-human animal actors.

Indeed, charity workers hold the idea that humans can manage nonhuman animal populations and thus keep the natural world in balance as absurd, part of the very problem they are trying to combat (and an example of why instrumental relations cannot enter the sphere of responsibility). The following view, provided by another member of the charity team, is indicative of the critique of conservation action, including culling, that they offer:

I would argue, that the ecosystem they [i.e. environmentalists] are trying to preserve is human defined. Sadly, the wildlife in Scotland and our countryside is not natural in any way. It has been manmade, constructed. If we left it truly to nature it wouldn't look anything like it does. So when they go in there and they say they are conserving the countryside, they are preserving their 
version of their countryside, for their own reasons. They are not conserving one species over another because that is what nature intended, it's because that's what they would rather see.

As the quote suggests, the contrast with environmentalism almost seems to licence a view of nature and the natural as ideology. Members of the animal protection organisation are highly sceptical of any claims made to act in defence of nature; or rather, they remain fixed on the practical consequences of those claims for individual animals. This does not lead them to propose a total lack of faith, but rather to favour a libertarian solution that opposes the notion of management altogether and imagines that nature should truly be allowed to determine its own outcomes. In response to my query about when human intervention in the countryside might be acceptable, the same staff member concluded, 'If I saw it happening and it wasn't something natural then yeah I would want to do something. But if it's part of nature I would think, leave nature alone. You know who am I to intervene?' This active abstention from unnatural intervention means letting the fox kill the capercaillie or pine marten. It means notionally allowing extinctions to occur. From this perspective, there is no redemption in human action, no possibility of a deliberative reintegration with nature. Rather animal protection seems to desire a natural world in which signs of human engagement are completely removed.

\section{Reconnection}

But this is not the whole story. Although charity workers don't regard humans as redeemable or morally responsible subjects in their instrumental management or care of environment and animal populations, they do identify a basis for renewal. For them, abstentionism or active non-intervention in the natural world, which includes refraining from causing animal suffering, is a necessary though not sufficient step. Animal protection should also be about self-awakening, the discovery or recognition of natural feeling within oneself. As one would expect, this 'form of subjectivation' (Foucault 1990) inevitably 
connects to the way human subjects interact with their non-human animal contemporaries.

In addition to submitting evidence and witness testimony to the Rural Affairs \& Environment Committee of the Scottish Parliament, the animal protection charity sought to influence the passage of the Bill in other ways. Like the lobbyists from the shooting estates and conservation bodies, Maggie devoted much time to seeking out and attending one-on-one interviews with the relevant government ministers, civil servants, MSPs and political party spokepersons on animal welfare or wildlife and countryside management issues. As well as providing scientific support for the charity's claims about the levels of suffering among trapped animals, she always showed these individuals photographic images and video footage, usually taken by the investigations officer, of creatures caught in snares. Indeed, she viewed this task as a crucial part of the work of lobbying. Maggie wanted to make sure that everyone involved in the drafting and redrafting of the Bill saw how cruel snaring could be and hence what their ethical responsibilities were. While she knew this kind of submission did not count as proper 'evidence' in the estimations of ministers, committee members or civil servants, she persisted with it because she believed the images might distress them enough to prick their consciences and change their minds. How could anyone continue to support the use of snares after seeing what they did to individual animals? This, then, was an unabashed appeal to human feeling and to what Maggie and her colleagues at the charity termed as 'empathy'.

The category is crucial to an understanding of how redemption and reintegration with nature might be conceived. For charity workers, empathy or the power to imaginatively experience the feelings of another is a key human instinctive capacity, vital to the development of an ethical life. This includes the ability to feel non-human animal joy and suffering. As one staff member told me, 'when every child is born they have a connection with animals.' The tragedy is that as the child grows into society he or she is taught to lose that connection and instead develop sets of unnatural reactions that result in detachment, animal cruelty and exploitation. Drawing on literature in child protection (see Myers Jr. 2013), an area at least one member of staff had previously worked in, the charity claims that the withdrawal of this empathy 
and sympathetic relationship to animals also explains cruelty and abuse between humans. There is a strong sense, then, of an ethical sensibility lost but still latent within us that if recovered might radically reconstitute not just human-animal relations, but also relations between people. In showing the images of trapped creatures Maggie is therefore simply aiming to revive a basic humanity, to enable subjects to reconnect.

Such a strategy was based in sound experience from another domain of the charity's work, the field of public campaigning. Like many animal rights organisations (see Song 2010), it had found that the display or publication of images of animal cruelty was a highly successful way of engaging supporters in particular issues and persuading them to 'take action'. In the case of the 'Ban Snaring' campaign, photographs and footage of foxes or badgers caught and struggling in snares or of the sometimes horrific injuries that killed them were crucial components that led individuals to sign petitions, fill out the template and send a letter to local MSPs or donate money. The images were regularly used in public talks and debates, school visits and on election hustings. Maggie also displayed them at stall presentations during the annual conferences of the main political parties, using the images to target ordinary delegates as much as the elected representatives. Indeed, at conference fringe meetings organised to discuss snaring, she regularly chose to illustrate her talk with a slideshow of animal suffering. Video footage of injured, distressed or dead trapped creatures often played on a continuous loop throughout the Q\&A sessions that followed, provoking supportive but notably passionate, angry or tearful contributions from the floor. Before leaving such events, many of those present committed themselves to campaign for a ban on snaring, to lobby their parliamentary and local authority representatives and other branch party members.

To Maggie, the response of the delegates at these fringe meeting was not unexpected. There seems an assumption that snares, or at least images of animals trapped in snares, have the power to radically impact an audience and motivate grassroots dissent. Like other members of the animal protection charity, she views the public reaction as entirely 'natural.' Indeed, she believes that these images work precisely because they draw out 'innate connections'. Snares, then, may act as instruments of predator control and 
animal suffering, but once reproduced and displayed in campaign literature and media, they can also become a kind of empathy-making machine, eliciting or trapping human feeling for the snared creatures.

This idea of an ethics that needs to be aggressively sparked or reignited through mediated encounters with suffering is essential. It informs not just the way Maggie and other charity workers figure the power of images to instil empathy (or snare an audience), but also their broader sense of how human subjects come to ethical awareness. Individuals, for instance, consistently told me that they first developed a sense of their own moral obligations to non-human animals through encounters or personal experiences with particular creatures. Accounts of these relationships, often begun in childhood, remain crucial for them, to the extent that they tend to subsume the formal giving of reasons or moral logic such as the language of rights. In fact, it was this original feeling or experience of empathy with an animal, usually a household pet, that usually led them to later seek out and discover the literature on animal cruelty and animal rights and to involve themselves in campaigning. The chronology is important because it explains charity members' attitude to abstract moral reasoning and deployment of scientific evidence. While staff regularly make use of both-the latter in part because it is the required form of legislative lobbying —and regard them as valuable, they are ultimately treated as secondary means of persuasion and after-the-fact confirmatory methods for reaching an ethical stance. For charity workers claim that they already instinctively know that animals are sentient, just as they already know through their own encounters that individual nonhuman creatures can possess distinctive personalities. As a natural or innate kind of human knowing, such a basis for morality is, they hold, vitally democratic. The animal protection charity believes that empathy can be potentially reawakened in everyone, humanity retrospectively revealed as natural after all.

\section{Conclusion}

To me, the notion of the charity workers seems to chime with an idea of ethics as 'disruptive event' (Smith 2011: 33-34; \& see Levinas 2003), an 
occurrence that dramatically interrupts commonplace and self-oriented interests. As Smith highlights, such a happening may be understood as motivated and delivered through direct or mediated experience of a singularity that is not one's own and which thus forces recognition of responsibility; although the encounter is with an individual being, it seems to call forth a wider concern, for like beings in equivalent situations (such as all creatures trapped in snares). Indeed, Smith postulates that this kind of 'fellow feeling' (2011: 27), invoked and re-invoked by attention and response to the appearance of another, is perhaps a more accurate reflection of how ethical obligation and evaluation grows.

This may be so, but that attention to the fellow feeling sparked by appearances, including images of snared creatures, does not however lead charity workers to consciously challenge or redefine their vision of nature. Unlike Smith (2011: 38), they do not suggest that one might begin to consider it as a dynamic process of manifestation, 'the continual unfolding of existence into the phenomenal world of appearances'. Equally, they do not seek to critique the treatment of nature as a 'premature assemblage' (Latour 2004) or to re-narrate the human within the natural through a focus on relatings (Haraway 2008). For them, nature is still self-evidently nature, and remains valued as a whole ethically. This is so despite the fact that they offer stringent critiques of the ways others construct nature; they are quite prepared, for instance, to reveal its ideological foundation in the hands of conservationists. Although environments may be denatured and our treatment of animals dominated by instrumental and unnatural acts (typified by the laying of snares), faith exists that natural feeling persists and, if human action allows, can even flourish.

\section{Acknowledgment}

I would like to thank all the members of the animal protection charity that I work with, including past and current staff. My thanks to Katie Dow and Victoria Boydell for inviting me to contribute to this special volume. I am also grateful for the comments and feedback of the reviewers, and those provided informally by Eeva Berglund, Matei Candea, Robin Irvine, Annelise Riles, Shari Sabeti and Tom Yarrow. Versions of this paper were given in anthropology department seminars at Durham, Maynooth and St Andrews, and I thank those audiences too. 


\section{References}

Berglund, Eeva. 1998. Knowing Nature, Knowing Science: Ethnology of Environmental Activism. Cambridge: The White Horse Press.

Bekoff, Marc [ed.]. 2013. Ignoring Nature No More: The Case for Compassionate Conservation. Chicago: University of Chicago Press.

Faubion, James. 2011. An Anthropology of Ethics. Cambridge: Cambridge University Press.

Foucault, Michel. 1990. The Use of Pleasure. Trans. Robert Hurley. New York: Vintage Books.

Franklin, Sarah. 2000. 'Life Itself: Global Nature and the Genetic Imaginary'. In Global Nature, Global Culture. [eds.] Sarah Franklin, Celia Lury, Jackie Stacey. London: Sage.

--. 2007. Dolly Mixtures: the remaking of genealogy. Duke University Press: Durham.

Haraway, Donna J. 1991. Simians, Cyborgs, and Women: the reinvention of Nature. Routledge: New York.

--. 2003. The Companion Species Manifesto: dogs, people, and significant otherness. Prickly Paradigm Press: Chicago.

--. 2008. When Species Meet. University of Minnesota Press: Minneapolis.

Laidlaw, James. 2010a. 'Ethical Traditions in Question: Diaspora Jainism and the Environmental and Animal Liberation Movements'. In Ethical Life in South Asia [eds.] Anand Pandian \& Daud Ali. Bloomington: Indiana University Press: 61-80.

--. 2010b. "Agency and Responsibility: perhaps you can have too much of a good thing.' In Ordinary Ethics: anthropology, language and action. [ed.] Michael Lambek. New York: Fordham University Press.

--. 2013. The Subject of Virtue: an Anthropology of Ethics and Freedom (New Departures in Anthropology). Cambridge: Cambridge University Press.

Lambek, Michael. 2010. 'Introduction'. In Ordinary Ethics: anthropology, language and action. New York: Fordham University Press.

Levinas, Emmanuel. 2003. Humanism of the Other. Urbana \& Chicago: University of Illinois Press. 
Myers Jr., Olin Eugene. 2013. 'Children, Animals, and Social Neuroscience: Empathy, Conservation Education, and Activism.' In Ignoring Nature No More: the Case for Compassionate Conservation. [ed.] Marc Bekoff. Chicago:

University of Chicago Press.

Rigby, Kate. 2011. 'Getting a taste for the Bogong Moth', Australian Humanities Review 50: 77-94.

Smith, Mick. 2011. 'Dis(appearance): Earth, Ethics and apparently (In)significant Others,' Australian Humanities Review 50: 23-44.

Strathern, Marilyn. 1992. After Nature: English kinship in the late twentieth century. Cambridge: Cambridge University Press.

Song, Hoon. 2010. Pigeon Trouble: bestiary biopolitics in a deindustrialised America. Philadelphia: University of Pennsylvania Press. 